\section{PRODUÇÃO DE CONHECIMENTO SOBRE GINÁSTICA NA ESCOLA: UMA ANÁLISE DE ARTIGOS, TESES E DISSERTAÇÕES}

\author{
PRODUCTION OF KNOWLEDGE ABOUT GYMNASTICS IN SCHOOL: \\ AN ANALYSIS OF ARTICLES, THESES AND DISSERTATIONS
}

PRODUCCIÓN DE CONOCIMIENTO SOBRE GIMNASIA EN LA ESCUELA: UN ANÁLISIS DE ARTÍCULOS, TESIS Y DISERTACIONES

\author{
Lucas Machado de Oliveira*, leda Parra Barbosa-Rinaldi**, \\ Juliana Pizani*
}

Palavras chave: Ginástica. Educação Física. Escola. Revisão.

Keywords: Gymnastics. Physical Education. School. Review.

Palabras clave: Gimnasia. Educación Física. Escuela. Revisión.
Resumo: Este estudo buscou analisar a produção de conhecimento sobre ginástica na escola no período de 1980 a 2018. Realizamos uma revisão integrativa de artigos publicados em periódicos nacionais e teses e dissertações dos programas de pós-graduação em Educação Física existentes no Brasil. Verificamos um total de 40 estudos sobre ginástica na escola e que o olhar para essa temática é restrito, não sendo suficiente para embasar a prática dos professores e contribuir para uma mudança no trato com o conteúdo gímnico dentro da escola. Acreditamos que reconhecer a importância dessa manifestação perpassa pela constituição de um conhecimento científico sólido sobre a ginástica, suas demandas e, sobretudo, suas possibilidades para a escola.

Abstract: This study analyzes production of knowledge about gymnastics at school from 1980 to 2018. We carried out an integrative review of articles published in journals and theses and dissertations of graduate programs in Physical Education in Brazil. We found 40 studies and concluded that views on the subject are restricted, not being enough to support teachers' practice and contribute to changes in the approach to gymnastics at school. We believe that recognizing the importance of gymnastics implies establishing solid scientific knowledge about it, its demands and above all, its possibilities for school.

Resumen: Este estudio buscó analizar la producción de conocimiento sobre gimnasia en la escuela en el período de 1980 a 2018. Realizamos una revisión integrativa de artículos publicados en periódicos nacionales y tesis y disertaciones de los programas de postgrado en Educación Física existentes en Brasil. Se verificó un total de 40 estudios sobre gimnasia en la escuela y que la mirada hacia esa temática es restringida e insuficiente como base para la práctica de los profesores y para contribuir a un cambio en el trato con el contenido de la gimnasia dentro de la escuela. Creemos que reconocer la importancia de esta manifestación pasa por la constitución de un conocimiento científico sólido sobre la gimnasia, sus demandas y, sobre todo, sus posibilidades para la escuela.
*Universidade Federal de Santa Catarina. Florianópolis, SC, Brasil E-mail:

lucasmdo@outlook.com; jupizani@hotmail.com

**Universidade Estadual de Maringá. Maringá, PR, Brasil. E-mail:

parrarinaldi@hotmail.com

Recebido em: 01-08-2019 Aprovado em: 04-02-2020 Publicado em: 22-03-2020 


\section{INTRODUÇÃO}

Essa pesquisa aborda especificamente a produção de conhecimento sobre a ginástica na escola ${ }^{1}$, pois a mesma é considerada como um saber instituído da educação física. Contudo, a literatura indica que a ginástica se encontra quase ausente do espaço escolar ou desenvolvida de forma incipiente (SOARES et al., 1992; BARBOSA-RINALDI; SOUZA, 2003; AYOUB, 2004; SCHIAVON; NISTAPICCOLO, 2007; SILVA et al., 2007; PIZANI; BARBOSA-RINALDI, 2010; BARBOSARINALDI; PIZANI, 2017).

Para tanto, tomamos como base de análise, artigos, teses e dissertações produzidos desde 1980, haja vista que, nesse momento o campo acadêmico se mostra com mais evidência, seja por meio de periódicos científicos, eventos, consolidação da pós-graduação stricto sensu, entre outros (BRACHT et al., 2011).

Nessa direção, é inegável que a produção de conhecimento na área da educação física tenha passado por uma sensível modificação. Isso porque, a expansão dos cursos de pós-graduação em nível de mestrado e doutorado imprime um ciclo de produção acadêmica, em que ao se ter um número maior de vagas de mestrado e doutorado, obtemos um acréscimo de teses e dissertações produzidas, que podem subsidiar a veiculação em forma de artigos em periódicos.

Essa conjuntura pode apontar demonstrativos sobre a área da ginástica na escola e as lacunas que ainda precisam ser preenchidas. Visualizamos estudos quem contemplaram a produção de conhecimento sobre ginástica (PEREIRA; ANDRADE; CESÁRIO, 2012; BEZERRA et al., 2014; SILVA et al., 2015; LIMA et al., 2016) e sobre ginástica na escola (LISBOA; TEIXEIRA, 2012). Estas pesquisas não recorreram à análise articulada de artigos, teses e dissertações tal como propomos nesse estudo. Assim, a pesquisa proposta avança em relação ao estabelecimento de um possível estado da arte sobre ginástica associada ao contexto escolar, justamente por considerar os diferentes tipos de produção, artigos em periódicos, teses e dissertações.

Por conseguinte, a opção por investigar a ginástica na escola tem relação direta com uma das lacunas para abordagem desse conhecimento na sociedade, haja vista que mesmo a ginástica sendo considerada um conhecimento clássico da educação física, esta ainda se apresenta distante da realidade escolar. Esse fenômeno estimula a curiosidade epistemológica balizada pela compreensão do que vem sendo estudado sobre a ginástica na escola e se suas propostas se constituem como facilitadoras para o trato do conhecimento gímnico. Nesse caso, mesmo havendo uma maior preocupação com a educação física escolar, não excluímos pesquisas que tratem dos demais espaços da escola, uma vez que entendemos que estes também são partícipes do processo de formação do aluno.

Considerando o exposto, buscamos analisar a produção de conhecimento sobre ginástica na escola no período de 1980 a 2018 por meio de uma análise de

\footnotetext{
1 A terminologia "ginástica na escola" será adotada nesse trabalho para tratar, num sentido amplo, tanto da ginástica presente na educação física como componente curricular obrigatório como também da educação física presente no contraturno escolar.
} 
artigos, teses e dissertações, com vistas à caracterização das pesquisas, bem como mapeamento das proposições para o cenário da educação física na escola. Por meio disso, esperamos contribuir com a construção de uma realidade favorável para a presença da ginástica no contexto escolar, fornecendo dados para a compreensão da constituição e caminhos da ginástica na escola. Além do mais, vislumbramos promover a reflexão sobre o trato com os saberes gímnicos, a fim de ampliar as possibilidades de intervenção na escola por meio da ginástica.

\section{METODOLOGIA}

A amostra foi constituída por artigos publicados em periódicos nacionais da área da educação física e por teses e dissertações produzidas nos programas de pósgraduação em educação física no Brasil, entre os anos de 1980 a 2018. A justificativa para este recorte temporal centra-se na diferenciação de técnicas padrões para constituição de estudo de revisões, em que visamos uma maior ampliação no alcance da busca e fidedignidade da mesma, o que aumenta a complexidade do processo. Essa dificuldade foi relatada por Bracht et al. (2011) que optaram por restringir sua pesquisa ao campo dos artigos, devido ao alto volume da produção e dificuldade de acesso às teses e dissertações. Para tanto, se fez necessária a elaboração de dois bancos de dados distintos, inclusive no método de coleta para cada um deles, sendo o primeiro de artigos e o segundo de teses e dissertações.

Para a coleta dos artigos, realizamos uma busca com palavras-chave que refletem a ginástica e seus campos de atuação: "ginástica", "ginásticas", "gímnica", "gímnicas", "gímnico", "gímnicos", "ginasta", "ginastas", "ginástico" e "ginásticos", "fitness" e "academia" em 11 periódicos nacionais da educação física: Revista Brasileira de Ciências do Esporte (RBCE), Movimento, Journal of Physical Education, Pensar a Prática, Licere, Motrivivência, Motriz, Revista Brasileira de Ciência e Movimento (RBCM), Revista Brasileira de Educação Física e Esporte (RBEFE), Revista Mackenzie de Educação Física e Esportes (RMEFE), Revista Brasileira de Cineantropometria e Desempenho Humano (RBCDH). Para a seleção da amostra, consideramos o escopo da revista, a qual precisava apresentar amplas produções sobre o campo da educação física. Dessa forma, periódicos com escopo explicitamente direcionado a áreas que não contemplam a ginástica foram excluídos. Além disso, as revistas deveriam ser nacionais e possuir classificação entre A1 e B3 para a área da educação física na avaliação do quadriênio 2013-2016 do Qualis-Periódicos.

Nesta etapa, realizamos a leitura dos títulos e resumos para identificarmos se os artigos de fato tinham como temática a área da ginástica. Feito isso, alocamos todos os artigos em um banco de dados organizado de forma cronológica de acordo com o ano de publicação dos trabalhos, contendo informações como autor, ano, título e periódico. Posteriormente, realizamos novamente a leitura dos títulos para selecionarmos os artigos que além de tratar da ginástica, vinculavam a temática ao contexto escolar. Ou seja, a busca dos artigos sobre ginástica na escola deriva de um banco de dados sobre ginástica em seu contexto geral de produção, isso porque, a busca direta por palavras-chave ou descritores nos bancos de busca online não reflete a realidade da produção vinculada à escola. 
No que se refere às teses e dissertações, considerando que existe uma defasagem na alimentação dos bancos de dados coletivos que disponibilizam este tipo de produção, optamos por realizar a coleta diretamente nos sites dos programas e complementar com a busca no Portal Domínio Público, Catálogo de Teses e Dissertações da CAPES e nas Bibliotecas Digitais das instituições de ensino superior responsáveis pela oferta dos programas de pós-graduação pesquisados, eliminando possíveis duplicidades encontradas. Ao fim, embora existam 32 instituições que oferecem cursos de pós-graduação em educação física em nível de mestrado e doutorado (CAPES, 2019), em oito deles não foi possível realizar a coleta das teses e dissertações em função da criação do programa ser recente e não ter resultado em nenhuma produção até o momento ou não haver disponibilidade dos arquivos para download.

Pelo fato de nem todos os programas disponibilizarem a ferramenta de busca, não podemos utilizar como recurso palavras-chave e/ou descritores. Sendo necessária a elaboração de um banco de dados com todas as pesquisas encontradas, contemplando todas as áreas para somente depois identificarmos as pesquisas que abordam a ginástica associada à escola. Assim, para selecionar a amostra sobre o tema da ginástica articulada à escola, adotamos como critérios de inclusão: teses e dissertações em português que tratam da ginástica correlacionada com a escola em seus títulos e/ou resumos. Já os critérios de exclusão eram publicações duplicadas ou incompletas. Após a constituição do banco geral de teses e dissertação, realizamos uma busca na lista de títulos, utilizando a ferramenta "Localizar" do Excel, com as mesmas palavras-chave utilizadas na busca dos artigos. Na sequência fizemos a leitura dos títulos e resumos dos estudos para um refinamento e seleção das pesquisas que tratem somente da ginástica associada à escola.

Considerando a falta de atualização nas Bibliotecas Digitais das IES, nos anos de 2017 e 2018 realizamos a busca manual no Catálogo de Teses e Dissertação da CAPES, Google e Portal Domínio Público a partir das palavras-chave utilizadas anteriormente para obtermos o maior mapeamento possível. A Figura1 apresenta a síntese das etapas de constituição da amostra.

Figura 1 - Síntese das etapas de revisão integrativa para os artigos, teses e dissertações

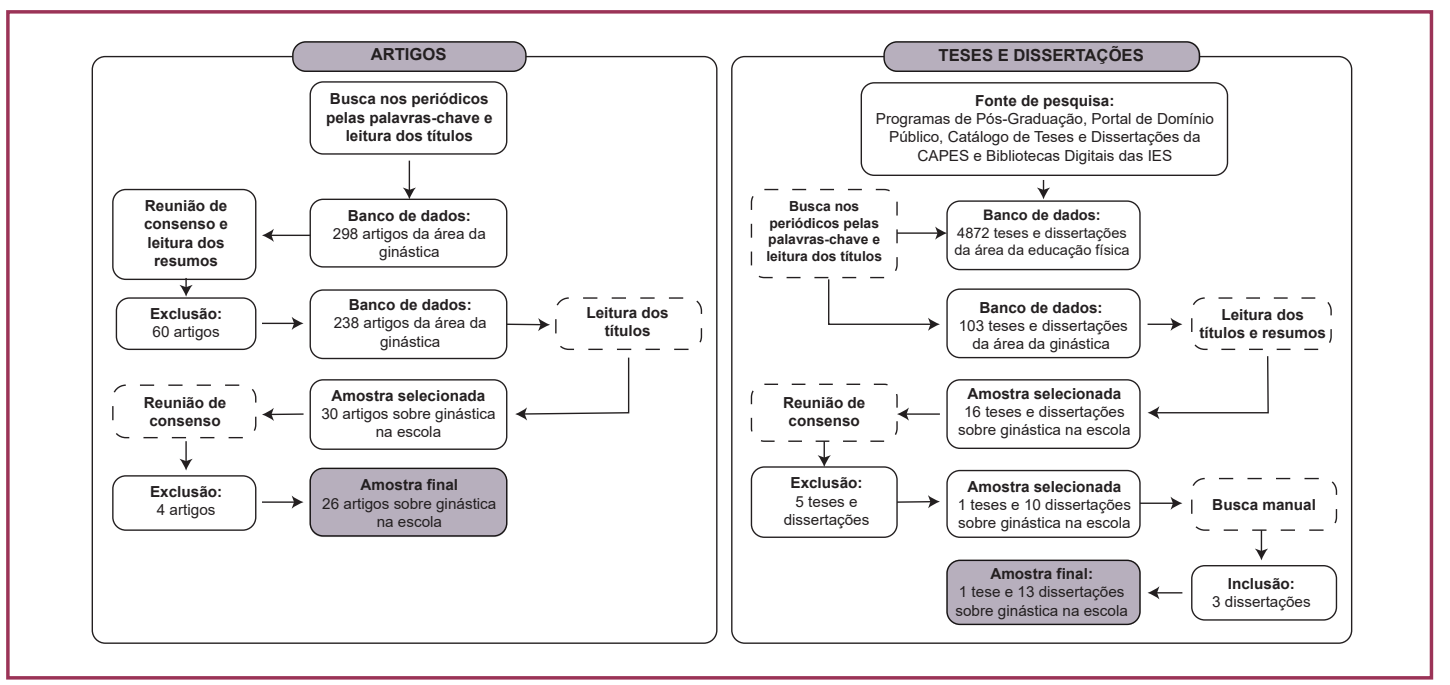

Fonte: dados da pesquisa. 
As produções incluídas focam exclusivamente a ginástica na escola, sendoassim, os estudos que tratavam tanto da ginástica, como dos diferentes temas da educação física escolar (esportes, dança, lutas etc.) não foram considerados nesta revisão. Isto se fez necessário para termos uma representação mais fidedigna e específica do trato da ginástica no contexto escolar. Também foram excluídos os estudos do tipo revisão, ponto de vista e/ou resumo. Todo processo foi realizado por dois pesquisadores e acompanhado de reuniões visando encontrar um consenso amostral.

Para a análise do estado da arte, tendo como finalidade a categorização das produções pesquisadas, bem como sua quantificação, recorremos à estatística descritiva e à técnica de análise de conteúdo proposta por Bardin (2016), a fim organizar os dados e qualificar a interpretação dos resultados.

O banco de dados de artigos, teses e dissertações foi elaborado contendo informações como: ano, autor(es), IES/periódico, título, temas, objetivo, características metodológicas, principais resultados, proposta etc. O tratamento dos dados se deu em três principais momentos: 1)classificação das pesquisas de acordo com os campos de atuação propostos por Souza (1997); 2) categorização das características metodológicas de acordo com as categorias propostas por Bracht et al. (2011); e, 3) classificação das pesquisas em propositivas e não propositivas após análise dos resultados e discussão, sendo que os estudos propositivos deveriam ter algum tipo de proposição objetivada e sistematizada para a ginástica na escola, podendo ser metodológica, pedagógica, curricular etc. e associada à educação física escolar, atividades desenvolvidas na educação de tempo integral ou projetos realizados no contra turno.

\section{RESULTADOS E DISCUSSÕES}

A amostra final foi composta por um total de 40 estudos entre artigos $(n=26)$, teses $(n=1)$ e dissertações $(n=13)$ relacionadas à temática ginástica na escola. Para análise consideramos estudos a partir de 1980 uma vez que nesse período surgiram as primeiras produções oriundas de programas de pós-graduação. Contudo, destacamos que a primeira e única tese que trata exclusivamente da ginástica na escola foi publicada somente em 1998 (AYOUB, 1998).

A fim de evidenciar a quantidade de estudos em cada periódico e programa de pós-graduação, apresentamos na Tabela 1 o volume da produção de acordo com o local de origem.

Tabela 1 - Quantitativo de estudos por periódico e programa de pós-graduação (1980-2018)

\begin{tabular}{ccc}
\hline Periódico & Produções sobre ginástica e escola & $\%$ \\
\hline RBCE & 6 & 23,08 \\
Movimento & 5 & 19,23 \\
Motrivivência & 5 & 19,23 \\
Pensar a Prática & 4 & 15,38 \\
Journal of Physical Education & 3 & 11,54 \\
RMEFE & 2 & 7,69 \\
RBEFE & 1 & 3,85 \\
\hline Total & $\mathbf{2 6}$ & $\mathbf{1 0 0}$ \\
\hline
\end{tabular}




\begin{tabular}{ccc}
\hline Programa de pós-graduação & Produções sobre ginástica e escola & \% \\
\hline UNICAMP & 6 & 42,86 \\
UFSC & 2 & 14,29 \\
UNESP-RC & 2 & 14,29 \\
UEM-UEL & 1 & 7,14 \\
UNIVASF & 1 & 7,14 \\
UPE-UFPB & 1 & 7,14 \\
USP & 1 & 7,14 \\
\hline Total & $\mathbf{1 4}$ & $\mathbf{1 0 0}$ \\
\hline & Fonte: dados da pesquisa. &
\end{tabular}

De acordo com Bracht et al. (2011), alguns periódicos da educação física são fortemente reconhecidos pelo seu potencial em fomentar e veicular conhecimentos relativos à educação física escolar. Para os autores, a RBCE, a Movimento, a Motrivivência e a Pensar a Prática são revistas com destaque na publicação de artigos sobre educação física escolar. Ao encontro disso, evidenciamos que a ginástica na escola apresenta maior difusão nesses mesmos periódicos, seguidos do Journal of Physical Education, RMEFE e RBEFE. Para além disso, a seguinte reflexão é cabível: dos onze periódicos incluídos nessa revisão, sete possuem publicações nesta temática, representadas por 26 estudos. Esse número tem sido suficiente para embasar a atuação do professor e promover a ginástica na escola? Schiavon e NistaPiccolo (2007) a partir de estudos que tiveram como foco a ausência da ginástica na escola, constataram que o principal motivo para a constituição desse cenário é a falta de conhecimento por parte dos professores. Dessa forma, entendemos que a melhoria dessa conjuntura perpassa por um aumento na quantidade de estudos que zelem pelas manifestações gímnicas na escola e que se apresentem de forma acessível e significante para os professores, superando a barreira que distancia o conhecimento científico do cotidiano escolar.

No que tange os programas de pós-graduação, destacamos que das 24 instituições que oferecem o curso de mestrado e/ou doutorado acadêmico em educação física com produções disponíveis para download, apenas sete delas possuem produções que articulam a ginástica e o contexto escolar. Nessa perspectiva, Lüdorf (2002) infere que a predominância de uma tendência em detrimento de outra, em uma universidade, pode estar atrelada ao desenvolvimento de linhas teóricas específicas a cada programa de pós-graduação que, por conseguinte, atendem os interesses do corpo docente.

Na mesma perspectiva, foram identificadas apenas 14 produções oriundas de programas de pós-graduação em nível de mestrado e/ou doutorado que fazem referência à ginástica na escola. Mesmo considerando a amplitude e diversidade temática que caracteriza a área da educação física, esse dado confere que é estreito o olhar dado à ginástica no contexto escolar. A problemática está firmada no momento em que consideramos a pós-graduação como, segundo Kokubun (2006), uma ferramenta de fomento para o desenvolvimento de uma área, multiplicando o potencial de seu sistema de pesquisa e subsidiando a formação de graduados com melhor instrução e habilidade para as suas funções na sociedade. Ou seja, com esse volume de conhecimento gerado nos programas de pós-graduação estamos 
contribuindo para efetivar a ginástica no ambiente escolar, bem como a formação de profissionais capacitados para trabalho com as manifestações gímnicas ou estamos apenas dando continuidade ao atual cenário de negligência com a temática?

Destacamos também o fato de que os programas de pós-graduação com maiores contribuições para a ginástica estão concentrados nas regiões Sul e Sudeste no Brasil. Uma possível explicação para isso é que a maioria dos grupos de pesquisa em ginástica cadastrado no diretório do Conselho Nacional de Desenvolvimento Científico e Tecnológico (CNPq) se encontra filiados a instituições localizadas no Sul e Sudeste do país (MARINHO; BARBOSA-RINALDI, 2010). Contudo, é importante pensar nos reflexos que essa centralização do conhecimento possui na tentativa de efetivar a prática gímnica nas escolas, sobretudo nas regiões do Brasil que estão alheias à produção conhecimento.

O programa de pós-graduação da UNICAMP possui a parcela majoritária no número de publicações sobre ginástica e escola. Dado este que corrobora com Oliveira et al. (2009), em que evidenciam que a UNICAMP é a instituição com maior representatividade em ginástica no Brasil em função de diversos fatores que favorecem a temática, tais como: matriz curricular da graduação e da pós-graduação, grupos de pesquisa, projetos de extensão e intercâmbio internacional com escolas especializadas em ginástica além dos festivais e fóruns fomentados pela instituição.

A Tabela 2 apresenta uma síntese de quais campos de atuação da ginástica, seguindo a divisão proposta por Souza (1997) e temas centrais são associados à essa manifestação na escola.

Tabela 2 - Percentual de estudos de acordo com campo de atuação de Souza (1997) e centralidade temática

\begin{tabular}{|c|c|c|c|}
\hline Campos de atuação & Tema central & $\%$ & $\%$ \\
\hline \multirow{4}{*}{ Competição } & Ginástica Artística & 12,5 & \multirow{4}{*}{27,5} \\
\hline & Ginástica Rítmica & 5 & \\
\hline & Combinado: Ginástica Artística e Ginástica Rítmica & 7,5 & \\
\hline & $\begin{array}{c}\text { Combinado: Ginástica Artística, Ginástica Rítmica e } \\
\text { Ginástica Acrobática }\end{array}$ & 2,5 & \\
\hline Condicionamento físico & Musculação & 2,5 & 2,5 \\
\hline \multirow{2}{*}{ Demonstração } & Ginástica Para Todos & 12,5 & \multirow{2}{*}{15} \\
\hline & Ginástica de Grande Área & 2,5 & \\
\hline \multirow{2}{*}{ Não se aplica } & Área da Ginástica & 40 & \multirow{2}{*}{55} \\
\hline & História da Ginástica & 15 & \\
\hline Total & & 100 & 100 \\
\hline
\end{tabular}

Fonte: dados da pesquisa.

Constatamos que a maioria das produções não trata de um campo de atuação específico (55\%), seja pelo fato dos estudos abordarem como temática central a área da ginástica ${ }^{2}$ como um todo ou por tratarem do histórico dessa manifestação. Nessa perspectiva, o aparecimento da área da ginástica como tema mais explorado nos estudos, infere uma visão mais holística por parte dos autores. Além disso, destacamos a importância do conhecimento histórico evidenciado em 15\% dos

2 Utilizamos o termo "área de ginástica" para designar os estudos que, ao invés de tratar um tema específico, perspectivassem ela de forma mais ampla, como uma área de conhecimento. 
estudos, para compreender a constituição de uma área e trazer proposições para o seu futuro. Goellner (2012, p. 47) aponta que a contribuição da história para a área da educação física e dos esportes "traduz uma postura de investigação que permite conhecer mais profundamente as ideologias, os valores, os preconceitos, as premissas sobre as quais se fundaram essas práticas". O que, por conseguinte, entendemos como indispensável para a construção de contribuições futuras.

Com relação aos estudos que se alocam em algum campo de atuação específico, constata-se: ginásticas de competição (27,5\%), ginásticas de demonstração (15\%) e ginástica de condicionamento físico (2,5\%). Não foram encontrados estudos que tratassem exclusivamente dos campos: ginásticas de conscientização corporal e ginásticas fisioterápicas associadas à escola.

O destaque evidenciado nos estudos para as manifestações gímnicas competitivas, sobretudo as Ginásticas Artística e Rítmica, parece ser o mesmo dado na prática esportiva escolar. De acordo com Pizani e Barbosa-Rinaldi (2010), as ações que aparecem na educação física escolar são aquelas de cunho competitivo em virtude da veiculação do esporte-rendimento pela mídia e o consumo do espetáculo esportivo pela população. Nessa perspectiva, Barbosa-Rinaldi e Souza (2003) contribuem afirmando que essa realidade é reflexo do entendimento restrito que os professores atuantes nas escolas possuem sobre o universo gímnico que, por conseguinte, privam os alunos da vivência ampla do conteúdo e de seus campos de atuação. Portanto, entendemos que além do aporte midiático, a produção acadêmica possui uma tendência a vincular o âmbito escolar com as ginásticas de competição, limitando o referencial teórico que embasa o próprio processo formativo. Em contrapartida, alguns autores evidenciam a Ginástica Para Todos, modalidade de demonstração, como um dos conteúdos gímnicos e até mesmo estratégia para o trato da ginástica, que melhor se adequa as demandas que caracterizam a educação física escolar (NISTA-PICOLLO, 1995; SOARES, 1999; PIZANI; BARBOSA-RINALDI, 2010), entretanto ela é foco em apenas $12,5 \%$ dos estudos presentes nessa revisão.

Compreendemos a importância que as ginásticas de competição possuem como conteúdo da área, contudo, a prática dos professores não deve estar limitada a elas, assim como a amplitude do universo gímnico deve ser percebida e valorizada na produção científica para subsidiar as práticas profissionais com vistas à superação da ginástica como modelo impresso pela mídia. Destarte, apontamos os estudos que debatem as ginásticas de demonstração, mesmo que em quantidade reduzida, como uma forma de fomento à compreensão da ginástica para além dos moldes já estabelecidos.

A seguir, destacamos na Tabela 3 o tipo de pesquisa realizada em cada produção de acordo com as categorias estabelecidas por Bracht et al. (2011) sendo: (1) diagnóstico/descrição: abarca os estudos que se propõem a oferecer um panorama sobre temáticas próprias da educação física escolar; (2) intervenção: reúne os estudos referentes à ação pedagógica, desde elementos que antecedem a aula, o seu acontecimento e sucessão; (3) fundamentação: abrange estudos que oferecem suporte para a construção da educação física escolar, problematizando a bases teóricas que alicerçam as práticas pedagógicas; (4) outros: categoria criada em decorrência da impossibilidade de classificação de alguns estudos nas categorias já existentes. 
Tabela 3 - Tipo de pesquisa realizada de acordo com as categorias de Bracht et al. (2011)

\begin{tabular}{|c|c|c|c|c|c|}
\hline \multicolumn{6}{|c|}{ Artigos } \\
\hline Categoria & $\mathbf{N}$ & Subcategoria & $\mathbf{N}$ & $\%$ & $\%$ \\
\hline Diagnóstico/Descrição & 9 & Diagnósticos de contextos & 9 & 34,6 & 34,6 \\
\hline \multirow{3}{*}{ Intervenção } & \multirow{3}{*}{9} & Conteúdos/Trato didático-pedagógico & 6 & 23 & \multirow{3}{*}{34,6} \\
\hline & & Formação/Intervenção & 1 & 3,8 & \\
\hline & & Métodos de ensino & 2 & 7,7 & \\
\hline Fundamentação & 8 & Sociofilosóficos & 8 & 30,8 & 30,8 \\
\hline Total & 26 & & 26 & 100 & 100 \\
\hline \multicolumn{6}{|c|}{ Teses e dissertações } \\
\hline Categoria & $\mathbf{N}$ & Subcategoria & $\mathbf{N}$ & $\%$ & $\%$ \\
\hline \multirow{2}{*}{ Diagnóstico/Descrição } & \multirow{2}{*}{4} & Diagnósticos de contextos & 3 & 21,4 & \multirow{2}{*}{28,5} \\
\hline & & Concepções de corpo, saúde, esporte & 1 & 7,1 & \\
\hline \multirow{2}{*}{ Intervenção } & \multirow{2}{*}{9} & Conteúdos/Trato didático-pedagógico & 8 & 57,2 & \multirow{2}{*}{64,3} \\
\hline & & Métodos de ensino & 1 & 7,1 & \\
\hline Outros & 1 & Não há subcategoria & 1 & 7,1 & 7,1 \\
\hline Total & 14 & & 14 & 100 & 100 \\
\hline
\end{tabular}

Fonte: dados da pesquisa.

Observamos que entre os artigos, existe um maior equilíbrio nas categorias, enquanto entre os estudos resultantes das teses e dissertações, a categoria intervenção apresenta predominância (64,3\%). Mendes (2016) ao revisar artigos, teses e dissertações sobre a avaliação da aprendizagem na educação física escolar encontrou um maior número de artigos de classificados em diagnóstico e fundamentação enquanto nas teses e dissertações verificou mais estudos classificados em diagnóstico e intervenção, não encontrando nenhum estudo de fundamentação. Além disso, em outras pesquisas de produção de conhecimento, citamos algumas análises de teses e dissertações que utilizaram uma outra categorização: Souza e Silva (1997) identificou predomínio da abordagem empírico-analítica $(66,22 \%)$ acima das abordagens fenomenológicohermenêutica $(21,62 \%)$ e crítico-dialética $(12,16 \%)$; anos mais tarde Lüdorf (2002) obteve resultado semelhante: abordagens empírico-analíticas (56,5\%), fenomenológicohermenêuticas (42\%) e crítico-dialéticas (1,5\%); assim como Frizzo (2010): abordagens empírico-analítico (73\%), fenomenológico-hermenêutica (23\%) e crítico-dialética (4\%). Isso pode ser reflexo da carga horária destinada à realização de estudos na pósgraduação, favorecendo estudos de intervenção que, normalmente, exigem maior tempo.

Com relação às subcategorias, verificamos a predominância de: diagnósticos de contexto, conteúdos/trato didático pedagógico e sociofilosóficos. Essas também foram prevalecentes na pesquisa realizada por Bracht et al. (2011) com artigos sobre educação física escolar publicados em nove periódicos da área, apontando certo tradicionalismo de vertentes na produção acadêmica. Isto é, de acordo com os autores, a predominância de uma categoria ou subcategoria em detrimento de outra tem relação com trajetória assumida pelos próprios periódicos em função das políticas editorais adotadas e além disso, está relacionada com o debate interno do próprio campo.

Ainda analisando o conteúdo das produções incluídas nessa revisão, identificamos quais estudos são propositivos (Quadro 1), bem como sob quais temáticas e objetivos são perspectivadas as propostas. 
Quadro 1 - Propostas identificadas nos estudos analisados

\begin{tabular}{|c|c|c|c|}
\hline $\begin{array}{l}\text { Autor } \\
\text { (Ano) }\end{array}$ & $\begin{array}{l}\text { Temática } \\
\text { central }\end{array}$ & Objetivo & Proposta \\
\hline $\begin{array}{l}\text { Ayoub } \\
(1998)\end{array}$ & $\begin{array}{l}\text { Ginástica } \\
\text { Geral }^{3}\end{array}$ & $\begin{array}{c}\text { Compreender como essa atividade [Ginástica Geral] vem se } \\
\text { manifestando na sociedade contemporânea e discutir quais são as suas } \\
\text { perspectivas para a Educação Física Escolar. }\end{array}$ & $\begin{array}{c}\text { Propõe um projeto de ginástica geral para as escolas } \\
\text { públicas, tendo como base a realização de um curso para } \\
\text { professores, seguida da aplicação e acompanhamento da } \\
\text { proposta nas aulas de educação física. }\end{array}$ \\
\hline $\begin{array}{l}\text { Toledo } \\
(1999)\end{array}$ & $\begin{array}{l}\text { Área da } \\
\text { Ginástica }\end{array}$ & $\begin{array}{l}\text { Oferecer subsídios para o ensino da ginástica na escola, através do } \\
\text { estudo de novas tendências na área educacional, como é o caso dos } \\
\text { "Conteúdos na Reforma", de César Coll et al. (1998). }\end{array}$ & $\begin{array}{l}\text { Aponta conteúdos para a área da ginástica escolar, } \\
\text { baseados na teoria de Coll. }\end{array}$ \\
\hline $\begin{array}{l}\text { Bonetti, } \\
(2000)\end{array}$ & $\begin{array}{l}\text { Área da } \\
\text { Ginástica }\end{array}$ & $\begin{array}{l}\text { Oferecer algumas contribuições teórico-metodológicas para fundamentar } \\
\text { a ginástica no âmbito da educação física escolar. }\end{array}$ & $\begin{array}{l}\text { Apresenta indicações teórico-metodológicas a serem } \\
\text { trabalhadas no ensino da educação física escolar, } \\
\text { especialmente no que se refere ao conteúdo da ginástica. }\end{array}$ \\
\hline $\begin{array}{c}\text { Schiavon } \\
\text { (2003) }\end{array}$ & $\begin{array}{l}\text { Ginásticas } \\
\text { Artística e } \\
\text { Rítmica }\end{array}$ & $\begin{array}{l}\text { Apontar alternativas para as dificuldades do desenvolvimento das } \\
\text { modalidades de ginástica artística e ginástica rítmica nas aulas de } \\
\text { Educação Física, auxiliando diretamente os profissionais atuantes nas } \\
\text { escolas. }\end{array}$ & $\begin{array}{c}\text { Aponta sugestões de conteúdos relacionados às } \\
\text { ginásticas artística e rítmica para as aulas de educação } \\
\text { física na escola. }\end{array}$ \\
\hline $\begin{array}{l}\text { Bueno } \\
(2004)\end{array}$ & $\begin{array}{l}\text { Ginástica de } \\
\text { Grande Área }\end{array}$ & $\begin{array}{l}\text { Resgatar e implementar esta manifestação da cultura corporal [ginástica } \\
\text { de grande área], oferecendo subsídios para a elaboração de trabalhos } \\
\text { desta natureza, contribuindo para a formação e atuação profissional do } \\
\text { professor de Educação Física no âmbito escolar e comunitário. }\end{array}$ & $\begin{array}{l}\text { Sugere possibilidades para o trabalho com a ginástica de } \\
\text { grande área na escola. }\end{array}$ \\
\hline $\begin{array}{l}\text { Bertolini } \\
(2005)\end{array}$ & $\begin{array}{l}\text { Ginástica } \\
\text { Geral }\end{array}$ & $\begin{array}{l}\text { Verificar se, através de um conjunto de ações interligadas, a viabilidade } \\
\text { do desenvolvimento desta metodologia [ginástica geral] seria possível } \\
\text { também na rede pública de ensino. }\end{array}$ & $\begin{array}{l}\text { Apresenta ações, conteúdos e metodologia para o } \\
\text { trabalho com a ginástica geral na escola. }\end{array}$ \\
\hline $\begin{array}{l}\text { Schiavon; } \\
\text { Nista- } \\
\text { Piccolo } \\
(2007)\end{array}$ & $\begin{array}{l}\text { Ginásticas } \\
\text { Artística e } \\
\text { Rítmica }\end{array}$ & $\begin{array}{l}\text { A partir de estudos que têm como foco de investigação as razões } \\
\text { da ausência da ginástica na escola, realizou-se uma pesquisa em } \\
\text { instituições de ensino formal da diretoria de ensino de Campinas (SP), } \\
\text { para verificar até que ponto o quadro diagnóstico encontrado é o mesmo } \\
\text { desenhado pelas conclusões apresentadas nesses estudos. }\end{array}$ & $\begin{array}{c}\text { Aponta sugestões de conteúdos relacionados às } \\
\text { ginásticas artística e rítmica para as aulas de educação } \\
\text { física na escola. }\end{array}$ \\
\hline $\begin{array}{l}\text { Seron et al. } \\
\quad(2007)\end{array}$ & $\begin{array}{l}\text { Área da } \\
\text { Ginástica }\end{array}$ & $\begin{array}{l}\text { Analisar como a ginástica pode ser desenvolvida na educação física } \\
\text { escolar a partir da metodologia do ensino aberto. }\end{array}$ & $\begin{array}{l}\text { Apresenta uma possibilidade de aplicação da ginástica } \\
\text { para os alunos na escola a partir do ensino aberto. }\end{array}$ \\
\hline $\begin{array}{l}\text { Ferreira; } \\
\text { Rodrigues } \\
(2014)\end{array}$ & $\begin{array}{l}\text { Ginástica } \\
\text { Geral }\end{array}$ & $\begin{array}{l}\text { Investigar a viabilidade de uma proposta pedagógica da prática da } \\
\text { ginástica geral nas escolas estaduais de Barra do Garças. }\end{array}$ & $\begin{array}{c}\text { Aponta meios de intervenção pedagógica no campo da } \\
\text { ginástica geral. }\end{array}$ \\
\hline
\end{tabular}

Fonte: dados da pesquisa

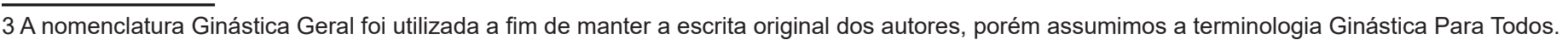

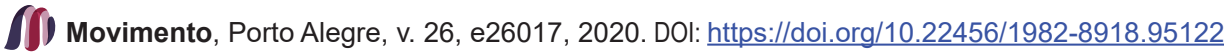


Dos 40 estudos que compõem a presente revisão, apenas 9 são propositivas $(22,5 \%)$. Esse dado nos leva a refletir sobre as implicações práticas do que está sendo produzido cientificamente, uma vez que, para além da quantidade, devemos nos importar com a qualidade do que se produz na perspectiva da teoria e de seu potencial de transformação da prática. Sobre essa relação teoria e prática, Souza (2001, p. 8) infere que é "na prática que a teoria tem seu nascedouro, sua fonte de desenvolvimento e sua forma de consecução, é na teoria que a prática busca seus fundamentos de existência e transfiguração". Assim, do ponto de vista pedagógico, a teoria e a prática devem coexistir. Do contrário, para Damasceno (1987) será simplesmente uma prática desprovida dos ingredientes teóricos e uma teoria alheia às mudanças que só ocorrem por meio da prática.

Anteriormente havíamos discutido sobre a relação inversamente proporcional entre a adequação que a Ginástica Para Todos possui no ambiente escolar e a quantidade de produções nessa perspectiva. Assim, quando nos debruçamos apenas nos estudos que apresentam alguma proposição notamos que há predominância de estudos nessa temática, isto é, $40 \%$ dos estudos com propostas para o trato com o conhecimento gímnico são relacionadas a Ginástica Para Todos, o que reforça as constatações dos autores citados sobre a viabilidade da ginástica de demonstração para o contexto escolar. Nesse sentido, reconhecemos que essa manifestação corresponde às demandas da educação física escolar, uma vez que a Ginástica Para Todos pode proporcionar o desenvolvimento da criatividade, ludicidade, participação e a busca dos alunos pela aquisição de novas interpretações, significados e possibilidades de expressão ginástica além da diversão e satisfação típicos da atividade (AYOUB, 2004).

Tratando o conteúdo das propostas, observamos que a maioria delas tende a trazer contribuições específicas para educação física como componente curricular, mas não tomam como foco o trato da ginástica no contexto extracurricular. Nessa perspectiva, notamos que as proposições consideram especialmente superar as dificuldades em relação ao espaço físico e formação profissional.

Se por um lado o conteúdo das propostas voltado diretamente para a educação física escolar é oportuno, a frequência com que se apresentam ainda é inócua para pensarmos a ginástica como conteúdo clássico da educação física escolar. Isso porque, identificamos uma maior linearidade entre estudos propositivos entre 1998 e 2007, a partir disso existe um intervalo de sete anos para a uma nova proposta, sendo em 2014 a última evidenciada. Assim, retomamos a reflexão sobre o suporte que a produção científica tem dado para o trato com o conhecimento gímnico na escola.

Cabe ressaltar a contribuição das propostas contidas em livros para área da ginástica no ambiente escolar. Embora a análise desse tipo de produção não tenha sido o foco da investigação, podemos citar: a sistematização dos saberes gímnicos para a educação física escolar (BARBOSA-RINALDI; PIZANI, 2017), a apresentação dos fundamentos que identificam cada ginástica (Ginástica Para Todos, Ginástica de Trampolim, Ginástica Aeróbica, Ginástica Rítmica, Ginástica Acrobática, Ginástica Artística) e a sugestão de atividades para desenvolvê-los (NUNOMURA, 2016), veiculação de propostas para a Ginástica Rítmica no ensino formal e não formal 
(PAOLIELLO; TOLEDO, 2010) como uma ferramenta norteadora para a construção de propostas para a área.

Isto posto, vale pensar qual é o caminho mais viável para elaboração e disseminação de propostas que abarquem o percurso percorrido pelos alunos durante a educação física na escola no que se refere à ginástica.

\section{CONSIDERAÇÕES FINAIS}

Constatamos que existe um olhar ainda restrito para a ginástica associada à escola na produção analisada e que isto caminha paralelamente com a atual conjuntura que coloca a ginástica como um conteúdo ausente ou quase ausente das escolas brasileiras. Além disso, apontamos para a inércia na elaboração de teses e dissertações sobre ginástica e escola. Esse fato nos leva a pensar como vem sendo conduzido e perspectivado o trato da ginástica na graduação e pós-graduação em educação física.

Destacamos que a falta de atualização dos bancos de dados online foi considerada como uma limitação do estudo. Esse cenário foi contornado, a medida do possível, com a busca em bancos diferentes, com o intuito de garantir a maior abrangência na constatação do estado da arte da produção sobre ginástica.

Entendemos que a produção de conhecimento é um contributo direto para o avanço do pensamento científico em relação à área da ginástica. Portanto, as pesquisas, precisam promover reflexão crítica de modo aprofundado para que possam contribuir com o desenvolvimento da ginástica no contexto escolar e com a formação integral do aluno. Nossos dados reafirmam o cenário pontuado há mais de uma década por Barbosa-Rinaldi e Souza (2003) quando asseveram que existe um círculo de desconhecimento da ginástica em diferentes contextos, reafirmado na universidade, local responsável pela produção científica e formação profissional. Existe assim, uma demanda urgente em proporcionar a esse diagnóstico um desfecho favorável e, para isso, acreditamos que o melhor caminho perpassa pela construção de um conhecimento científico sólido do que é a área da ginástica, quais seus desafios, contribuições e sobretudo, quais suas possibilidades para a escola. Para tanto, reforçamos outros ambientes dentro da universidade que podem dar suporte e fomentar à produção de conhecimento, tais como projetos de extensão, grupos de pesquisa e eventos científicos.

\section{REFERÊNCIAS}

AYOUB, Eliana. A ginástica geral na sociedade contemporânea: perspectivas para a educação física escolar. 1998. 187 f. Tese (Doutorado em Educação Física) - Faculdade de Educação Física, Universidade Estadual de Campinas, Campinas, 1998.

AYOUB, Eliana. Ginástica geral e educação física escolar. Campinas: Editora da UNICAMP, 2004. 
BARBOSA-RINALDI, leda Parra; PIZANI, Juliana. Saberes necessários à educação física na escola: a ginástica em foco. In: BORTOLETO, Marco Antonio Coelho; PAOLIELLO, Elizabeth (Org.). Ginástica para todos: um encontro com a coletividade. Campinas: Editora da UNICAMP, 2017. Cap. 4. p. 67-85.

BARBOSA-RINALDI, leda Parra; SOUZA, Elizabeth Paoliello Machado. A Ginástica no percurso escolar dos ingressantes dos cursos de licenciatura em educação física da Universidade Estadual de Maringá e da Universidade Estadual de Campinas. Revista Brasileira de Ciências do Esporte, v. 24, n. 3, p.159-173, maio 2003. Disponível em: http:// revista.cbce.org.br/index.php/RBCE/article/view/769/443. Acesso em: 10 jul. 2019.

BARDIN, Lawrence. Análise de conteúdo. São Paulo: Edições 70, 2016.

BERTOLINI, Claudia Mara. Ginástica Geral na escola: uma proposta pedagógica desenvolvida na rede estadual de ensino. Dissertação (Mestrado em Educação Física) Faculdade de Educação Física, Universidade Estadual de Campinas. Campinas-SP, 2005.

BEZERRA, Liudmilla de Andrade et al. Ginástica na formação inicial em educação física: análise das produções científicas. Revista da Educação Física/UEM, v. 25, n. 4, p. 663673, set./dez. 2014. Disponível em: http://www.periodicos.uem.br/ojs/index.php/RevEducFis/ article/view/22689. Acesso em: 10 jul. 2019.

BONETTI, Albertina. Perspectivas teórico-metodológicas para a ginástica: alguns subsídios para redimensioná-la na Educação Física escolar. Motrivivência, n. 14, p. 221-230, maio 2000. Disponível em: https://periodicos.ufsc.br/index.php/motrivivencia/article/ view/5841/20396. Acesso em: 10 jul. 2019.

BRACHT, Valter et al. A Educação Física Escolar como tema da produção do conhecimento nos periódicos da área no Brasil (1980-2010): parte I. Movimento, v. 17, n. 2, p. 11-34, abr./ jun. 2011. Disponível em: https://seer.ufrgs.br/Movimento/article/view/19280/13146. Acesso em: 10 jul. 2019.

CAPES. Coordenação de Aperfeiçoamento de Pessoal de Nível Superior. Cursos recomendados e reconhecidos. Disponível em: https://sucupira.capes.gov.br/sucupiral public/consultas/coleta/programa/listaPrograma.

BUENO, Thais Franco. Ginástica de Grande Área: uma realidade possível no contexto escolar. Dissertação (Mestrado em Educação Física) - Faculdade de Educação Física. Universidade Estadual de Campinas, Campinas, 2004.

DAMASCENO, Maria Nobre. A relação teoria-prática na ação docente. Revista Educação em Debate, v. 10, n. 13, p. 40-51, jan./jun. 1987. Disponível em: http://www.periodicosfaced. ufc.br/index.php/educacaoemdebate/article/viewFile/495/301. Acesso em: 10 jul. 2019.

FERREIRA, Fabricio Gurkewicz; RODRIGUES, Minéia Carvalho. A prática pedagógica da ginástica geral nas escolas públicas de Barra do Garças (MT). Revista Mackenzie de Educação Física e Esporte, v. 13, n. 2, jul./dez. 2014. Disponível em: http://editorarevistas. mackenzie.br/index.php/remef/article/view/4937. Acesso em: 10 jul. 2019.

FRIZZO, Giovanni Felipe Ernst. A produção do conhecimento da educação física no século XXI: a pesquisa no programa de pós-graduação em ciências do movimento humano da UFRGS. Pensar a Prática, v. 13, n. 3, p. 1-16, set./dez. 2010. Disponível em: https://www. revistas.ufg.br/fef/article/view/8628/8393. Acesso em: 10 jul. 2019.

GOELLNER, Silvana Vilodre. A importância do conhecimento histórico na formação de professores de educação física e a desconstrução da história no singular. Kinesis, v. 30, n. 1, p. 37-55, jan./jun. 2012. Disponível em: https://periodicos.ufsm.br/kinesis/article/ view/5721/3935. Acesso em: 10 jul. 2019. 
KOKUBUN, Eduardo. Pós-Graduação em educação física. Revista Brasileira de Educação Física e Esporte, v. 20, supl. n. 5, p. 31-33, set. 2006. Disponível em: http://citrus.uspnet. usp.br/eef/uploads/arquivo/v\%2020\%20supl5\%20artigo5.pdf. Acesso em: 10 jul. 2019.

LIMA, Letícia Bartholomeu de Queiroz et al. A produção acadêmica em ginástica na pós-graduação em educação física das Universidades Estaduais de São Paulo. Revista Brasileira de Ciência e Movimento, v. 24, n. 1, p. 52-68, 2016. Disponível em: https:// portalrevistas.ucb.br/index.php/RBCM/article/view/6007/4260. Com acesso em: 10 jul. 2019.

LISBOA, Nubia dos Santos; TEIXEIRA, David Romão. A atualidade da produção científica sobre a ginástica escolar no Brasil. Conexões, v. 10, n. Especial, p. 1-9, dez. 2012. Disponível em: https://periodicos.sbu.unicamp.br/ojs/index.php/conexoes/article/ view/8637658. Acesso em: 10 jul. 2019.

LÜDORF, Sílvia Maria Agatti. Panorama da pesquisa em educação física da década de 90: análise dos resumos de dissertações e teses. Revista da Educação Física/UEM, v. 13, n. 2, p. 19-25,2002. Disponível em: http://www.periodicos.uem.br/ojs/index.php/RevEducFis/ article/view/3651/2520. Com acesso em: 10 jul. 2019.

MARINHO, Alcyane; BARBOSA-RINALDI, leda Parra. Ginástica: reflexões sobre os grupos de pesquisa cadastrados no diretório do CNPq. Revista da Educação Física/UEM, v. 21, n. 4, p. 633-644, 2010. Disponível em: http://www.periodicos.uem.br/ojs/index.php/RevEducFis/ article/view/8522/6768. Acesso: 10 jul. 2019.

MENDES, Evandra Hein. Avaliação da aprendizagem na educação física escolar: caracterização e habitus de professores do Paraná. 2016. 127 f. Tese (Doutorado em Educação Física) - Programa de Pós-graduação em Educação Física, Universidade Estadual de Maringá, Maringá, 2016.

NISTA-PICCOLO, Vilma Leni. Educação Física escolar: ser... ou não ter? Campinas: Editora da UNICAMP, 1995.

NUNOMURA, Myrian. Fundamentos das Ginásticas. 2. ed. Várzea Paulista: Fontoura, 2016.

OLIVEIRA, Maurício Santos et al. Pesquisa em ginástica: a produção da pós-graduação da Faculdade de Educação Física da UNICAMP. Conexões, v. 7, n. 1, 2009. Disponível em: https://periodicos.sbu.unicamp.br/ojs/index.php/conexoes/article/view/8637785/5476. Acesso em: 10 jul. 2019.

PAOLIELLO, Elizabeth; TOLEDO, Eliana. Possibilidades da Ginástica Rítmica. São Paulo: Phorte, 2010.

PEREIRA, Ana Maria; ANDRADE, Thais Nogueira; CESÁRIO, Marilene. A produção do conhecimento científico em ginástica. Conexões, v. 10, n. Especial, p. 56-79, 2012. Disponível em: https://periodicos.sbu.unicamp.br/ojs/index.php/conexoes/article/ view/8637662/5353. Acesso em: 10 jul. 2019.

PIZANI, Juliana; BARBOSA-RINALDI, leda Parra. Cotidiano escolar: a presença de elementos gímnicos nas brincadeiras infantis. Revista da Educação Física/UEM, v. 21, n. 1, p. 115-126, 2010. Disponível em: http://periodicos.uem.br/ojs/index.php/RevEducFis/ article/view/7732/5713. Acesso em: 10 jul. 2019.

SCHIAVON, Laurita; NISTA-PICCOLO, Vilma Leni. A ginástica vai à escola. Movimento, v. 13, n. 3, p.131-150, set./dez. 2007. Disponível em: https://seer.ufrgs.br/Movimento/article/ view/3572/1971. Acesso em: 10 jul. 2019. 
SCHIAVON, Laurita Marconi. O projeto crescendo com a ginástica: uma possibilidade na escola. 2003. 203f. Dissertação (Mestrado em Educação Física) - Faculdade de Educação Física, Universidade Estadual de Campinas, Campinas, 2003.

SERON, Taiza Daniela et al. A ginástica na Educação Física escolar e o ensino aberto.

Revista da Educação Física/UEM, v. 18, n. 2, p. 115-125, 2007. Disponível em: http://www. periodicos.uem.br/ojs/index.php/RevEducFis/article/view/3268/2334. Acesso em: 10 jul. 2019.

SILVA, Rafael Bernardo et al. Educação física escolar em Maringá: experiência de ensinoaprendizagem no cotidiano das aulas. Revista Brasileira de Ciências do Esporte, Campinas, v. 28, n. 2, p. 69-83, jan. 2007. Disponível em: http://www.periodicos.uem.br/ojs/ index.php/RevEducFis/article/view/3268/2334. Acesso em: 10 jul. 2019.

SILVA, Deisy de Oliveira et al. O estado da arte da ginástica nos anais do Fórum Internacional de Ginástica Geral de 2001 a 2012. Conexões, v. 13, n. Especial, p. 211-229, 2015. Disponível em: https://periodicos.sbu.unicamp.br/ojs/index.php/conexoes/article/ view/8637585/pdf 51. Acesso em: 10 jul. 2019.

SOARES, Carmem Lúcia et al. Metodologia do ensino da educação física. São Paulo: Cortez, 1992.

SOARES, Carmem Lúcia. O corpo, o espetáculo, a ginástica. In: FÓRUM BRASILEIRO DE GINÁSTICA GERAL,1., 1999. Anais... Campinas: Universidade Estadual de Campinas, 1999. v. 1, p.19-21.

SOUZA, Nadia Aparecida. A relação teoria-prática na formação do educador. Semina: Ciências Sociais e Humanas. Londrina, v. 22, p. 5-12, set. 2001. Disponível em: http:// www.uel.br/revistas/uel/index.php/seminasoc/article/view/3868/3108. Acesso em: 10 jul. 2019.

SOUZA, Elizabeth Paoliello Machado. Ginástica Geral: Uma área do conhecimento da Educação Física. 1997. 163 f. Tese (Doutorado em Educação Física) - Programa de PósGraduação em Educação Física, Universidade Estadual de Campinas, Campinas, 1997.

TOLEDO, Eliana. Proposta de conteúdos para a ginástica escolar: um paralelo com a teoria de Coll. 1999. 215f. Dissertação (Mestrado em Educação Física) - Faculdade de Educação Física, Universidade Estadual de Campinas, Campinas, 1999. 